\title{
Two's company? Solitary vixens' motivations for seeking social contact
}

\author{
Anne Lene Hovland ${ }^{\mathrm{a}, *}$, Anne Kathrine Akre ${ }^{\mathrm{a}}$, Andreas Flø ${ }^{\mathrm{b}}$, Morten Bakken ${ }^{\mathrm{a}}$, \\ Tarja Koistinen ${ }^{\mathrm{c}}$, Georgia J. Mason ${ }^{\mathrm{d}}$ \\ a Norwegian University of Life Sciences, Department of Animal and Aquacultural Sciences, P.O. Box 5003, NO-1432 Ås, Norway \\ b Norwegian University of Life Sciences, Department of Mathematical Sciences and Technology, P.O. Box 5003, NO-1432 Ås, Norway \\ c University of Eastern Finland, Department of Biosciences, P.O. Box 1627, FI-70211 Kuopio, Finland \\ d Department of Animal and Poultry Science, University of Guelph, Guelph, Ontario, Canada N1G 2W1
}

\section{A R T I C L E I N F O}

\section{Article history:}

Accepted 4 October 2011

Available online 24 October 2011

\section{Keywords:}

Social behaviour

Fox

Motivation

Operant method

Aggression

Play

\begin{abstract}
A B S T R A C T
The flexible social organisation in red foxes (Vulpes vulpes) suggests that social contact could enrich the housing of silver fox vixens (a selected line of red foxes) farmed for their fur. To investigate their social motivation, adult vixens housed in an operant apparatus were allowed to pull a loop for full physical contact with a same-aged vixen. The access cost was increased daily and their maximum price paid (MPP) measured. Five test and five stimulus animals were pair housed long-term in separate apparatuses over 5 weeks in November/December wherein each pair could have $12 \mathrm{~h}$ daily physical contact in a shared compartment. Prior to the operant trials, two food competition tests were completed to establish dominance relations within pairs. To examine vixens' motives for contact, social behaviour during interaction was also recorded. Subsequently, the test foxes' MPP for a comparator resource, food, was also measured and their relative price paid (RPP, \%) for contact calculated. When access to the resource cage was free (FR1), at the start and end of the experiment, time spent in contact averaged approximately $1 / 6(2 \mathrm{~h})$ of the available time; this was stable between these periods. Neither visit rate to nor time spent in the shared compartment differed between the start and the end of the trial, indicating that the test subjects' social motivation remained stable during the experimental period. The MPP (mean \pm SE) for social contact averaged at $560 \pm 160.6$ pulls; this was significantly lower $(P=0.015)$ than the MPP for food $(2108 \pm 526.6$ pulls $)$, representing a RPP of $24.8 \pm 3.36 \%$. During social interaction agonistic gaping signals occurred (though never serious fights requiring intervention), but there were also bouts of play, social exploration and high levels of synchronous resting. Aggressive behaviour during the second food test predicted the levels of aggression during operant trials. RPP positively correlated with the total time spent together $(r=0.87, P=0.054)$, and with the time spent resting together $(r=0.89, P=0.046)$. Differences in RPPs for contact and levels of agonism between pairs illustrate that social contact between adult vixens is enriching for some, but may put welfare at risk for others, especially if they have no opportunity to retreat from aggression. However, levels of agonistic behaviour during, e.g. food competition tests may be a possible indicator of the compatibility between potential cage mates. Due to the low number of animals the result must now be replicated with further animals.
\end{abstract}

(c) 2011 Elsevier B.V. All rights reserved.

\footnotetext{
* Corresponding author. Tel.: +47 649651 68; fax: +47 64965101.

E-mail address: anne.hovland@umb.no (A.L. Hovland).
}

\section{Introduction}

Silver foxes (Vulpes vulpes) are kept commercially for their fur and are typically housed in wire mesh cages with access to gnawing objects, shelves and sometimes also nest 
boxes. Adult vixens kept for breeding purposes are, except for the whelping season, housed singly throughout their entire lives. These traditions may be based on assumptions that farmed adult vixens have limited needs for social contact, especially since they are housed in transparent cages that allow visual, olfactory and auditory communication between conspecifics. Furthermore, full contact between adult vixens kept in connected cage systems can sometimes result in severe fights, due to, e.g. competition for social dominance, causing injuries and stress to the animals (Hovland et al., 2010). However, red fox vixens in the wild often live in social groups consisting of both related and unrelated females (Iossa et al., 2009), and here females' social interactions include amicable allo-grooming and play (Macdonald et al., 2004), although aggressive displays can still escalate into fights (White and Harris, 1994). The social dynamics within free-living groups of foxes depend on factors like food predictability and resource competition (e.g. Baker et al., 2000), as well as seasonal fluctuations in reproductive hormones (Harris and White, 1992). That red fox vixens can naturally establish positive social relations in female groups forms a basis for examining whether social contact could enrich the housing environment of farmed silver fox vixens. However, due to the variation in natural sociality - some red fox vixens live just with a male (Cavallini, 1996) - it is important to establish to what extent adult vixens are motivated for full social contact when housed in a farm environment, how variable this is, and what their motives are for seeking contact. If motivation for contact is low and/or motives for seeking contact are competitive and aggressive, we can infer that social contact would compromise welfare (e.g. Hovland et al., 2006). On the other hand, if motivations for contact are high and/or are followed by positive interactions such as play (Oliveira et al., 2010), mutual grooming (Feh and de Mazieres, 2003) or social resting (Van Loo et al., 2004) then we can infer that social contact would enhance welfare.

Strength of motivation is commonly examined by allowing animals to work for access to resources (Kirkden and Pajor, 2006; Jensen and Pedersen, 2008), for example, pushing weighted doors or performing learned operant responses like lever pressing. These resources may also include potential social partners (e.g. Holm et al., 2002; Patterson-Kane et al., 2002; Seaman et al., 2008). One measure of motivational strength is the maximum price paid (or 'reservation price'): the highest price the animal is willing to pay for a single visit to the resource (e.g. Mason et al., 2001; Kirkden et al., 2003). To calculate the relative importance of a resource food is sometimes used as a 'yardstick' or comparator resource (e.g. Pedersen et al., 2002). Using this approach, Hovland et al. (2008) examined the strength of social motivations in sub-adult female silver foxes using a 'closed-economy' operant apparatus in which animals were housed continuously and able to decide their own interaction time with conspecifics after paying an access fee that was increased daily until the maximum price was reached. In the present study, we modified the same set-up to measure the strength of social motivation in these vixens as adults, relative to their motivation for food. We also examined the vixens' motives for seeking social contact by recording in detail their agonistic and affiliative behaviours during interactions with the companion animal. Finally, we collected data to assess the stability of social responses over time, and the degree and causes of variation in social motivation between subjects.

\section{Material and methods}

\subsection{Experimental animals, feeding and housing}

Ten 3.5-year-old vixens originating from a standard commercial line participated in the study. They were randomly separated into five pairs that had had no previous physical contact. In the social operant test, five vixens acted as test subjects while the other five were companions or stimulus animals. All foxes had previously participated in a similar operant experiment as sub-adults/juveniles and details on their training as cubs is described in Hovland et al. (2008). Then, they were tested in different pairs from the ones they were placed in as adults. Prior to food competition tests (see below) and testing in the operant apparatus, vixens were housed singly in a traditional uninsulated fox house in a standard cage $(1.20 \mathrm{~m} \times 1.06 \mathrm{~m} \times 0.76 \mathrm{~m})$ made of plastic coated wire mesh with access to a nest box, resting shelf and wooden gnawing stick. Food (food paste for fur animals: Pelsdyrfôr Hamar AB) was provided ad libitum once daily and water was freely available from drinking nipples. During food competition tests each pair was housed inside one standard cage for as long as the test lasted (see Section 2.2); while during the operant testing they were housed continuously inside the apparatus.

\subsection{Testing dominance relations: the food competition test}

Since dominance relations may influence foxes' social preferences (Akre et al., 2010a,b), one goal was to investigate whether dominance relationships affected foxes' motivation to work for social contact. To assess dominance relations within each of the 5 pairs, food competition tests (Bakken, 1993) were completed before the onset of the operant experiment. This test consisted of a contest between two foxes over a restricted amount of food. Prior to testing, vixen pairs were housed in a single cage $(1.20 \mathrm{~m} \times 1.06 \mathrm{~m} \times 0.76 \mathrm{~m})$ with access to a food tray, drinking nipple and a resting shelf. In each pair, one fox was individually marked by removing a small amount of fur from the tail tip. Animals were fed ad libitum the first day but to ensure high feeding motivation they were starved the second and fourth day before the first (3rd day) and second (5th day) competition test. The food competition test was performed by one observer who positioned a small amount of food paste $(100 \mathrm{~g})$ on the food tray before withdrawing $2.5 \mathrm{~m}$ from the cage for the total test duration $(1.5 \mathrm{~min})$. The fox that defended and ate all the food was recorded as the winner and thence the dominant. Agonistic behaviour was also recorded by direct observation during the first day after pairing $(6 \times 20 \mathrm{~min})$ and on the evening of the second day $(3 \times 20 \mathrm{~min})$. The observer was visible to the animals and positioned outside the fox house, 5-7 $\mathrm{m}$ from their cages. Prior to the start of recordings there was a $5 \mathrm{~min}$ period for habituation to 
Table 1

The individual reinforcement schedules that were selected and implemented for each test subject in the operant tests, illustrated by showing the required number of pulls for access to the resource on certain testing days over the course of the experiment. The previous maximum price paid as sub-adults (MPP sub), which acted as basis for these calculations, is also included.

\begin{tabular}{|c|c|c|c|c|c|c|c|c|}
\hline Test fox & MPP sub & Day 1 & Day 7 & Day 14 & Day 21 & Day 28 & Day 35 & Day 40 \\
\hline 1 & 2112 & 1 & 160 & 832 & 1840 & 2848 & 4304 & 5344 \\
\hline 2 & 2240 & 1 & 160 & 832 & 1840 & 2848 & 4304 & 5344 \\
\hline 3 & 2368 & 1 & 160 & 832 & 1840 & 2848 & 4304 & 5344 \\
\hline 4 & 1984 & 1 & 160 & 608 & 1504 & 2512 & 3520 & 4240 \\
\hline 5 & 224 & 1 & 24 & 80 & 136 & 224 & 400 & 560 \\
\hline
\end{tabular}

the observer. Behaviours recorded included low-intensity aggressive signals (agonistic gaping, back arching), physical aggression (upright, blocking, mounting), fighting, positive interactions (grooming and play) (see Table 2 for further description) and other behaviours (sit, stand, walk, rest). Foxes were scanned every 30th s using 3-4 s observation time for each pair. Behaviours were recorded as events using instantaneous sampling. After competition tests were finished all foxes were fed double quantity food rations to compensate for the previous restriction. Food competition tests were completed 22-26 October (Food Test 1) and 21-25 November (Food Test 2). Foxes were kept under close supervision with checks $(0800 \mathrm{~h}, 1400 \mathrm{~h}$ and $2100 \mathrm{~h}$ ) during the test period to enable intervention in case of serious aggression.

\subsection{The operant apparatus and assessment of motivational strength}

Each operant apparatus consisted of four cage units made of standard, plastic-covered wire mesh (see Fig. 1). To ensure that social interaction only took place in the resource cage, and prevent foxes from entering each other's home cages, a door-lock system and collars were used (see details below). The central operant cage was attached to a resource cage and a control cage, and the stimulus fox home cage was attached to the resource cage. The operant cage was the test subject's 'home': thus a feeding tray, drinking cup and a resting platform were mounted here, along with two operanda located on opposite walls. The stimulus fox cage adjoining the resource cage was the home cage of the 'companion' and so also contained feeding trays, drinking cups and platforms. However, the space in this cage was restricted (to one third that of the test fox's home cage: see Fig. 1) in order to motivate the stimulus fox (i.e. the resource) to utilise the resource cage, which it could freely access during experimental hours. The test subject had access to both the resource cage and the control cage, but could not enter the stimulus fox home cage. The stimulus fox (i.e. the companion) could access the stimulus fox cage and the resource cage only.

During the experiment, increasing costs were imposed for access by the test fox to the resource cage, but the control cage was always maintained at almost free access (fixed ratio of 1, FR1). This was to control for the effect of the extra space provided in the resource cage, and thus to ensure that motivations to access the resource cage could be attributed to the presence of the companion and not the cage itself. Two aluminium one-way gates, one for entrance and one for exit connected each pair of cage units (for a more detailed description, see Hovland, 2005), both equipped with micro-switches for the exact logging of time data. The test subject and stimulus fox each wore a metal collar for opening the exit gates, equipped with a transmitter in a PVC cover measuring $50 \mathrm{~mm} \times 30 \mathrm{~mm} \times 57 \mathrm{~mm}$. The total weight of collar and transmitter was $160 \mathrm{~g}$. A rubber-coated metal chain $(42 \mathrm{~cm})$ shaped as a loop acted as the operandum for the test vixen. The force required for a validated pull could be varied, but was set at $0.5 \mathrm{~kg}$ during the experiment. To register the number of completed pulls, a micro-switch was mounted on the operandum and connected to a computer interface (LabView, National Instruments). To allow the test fox to enter the resource (or control) cage, the computer counted the required number of pulls and signalled to a gate controller mounted on top of the gate to open the access door. During the experiment,

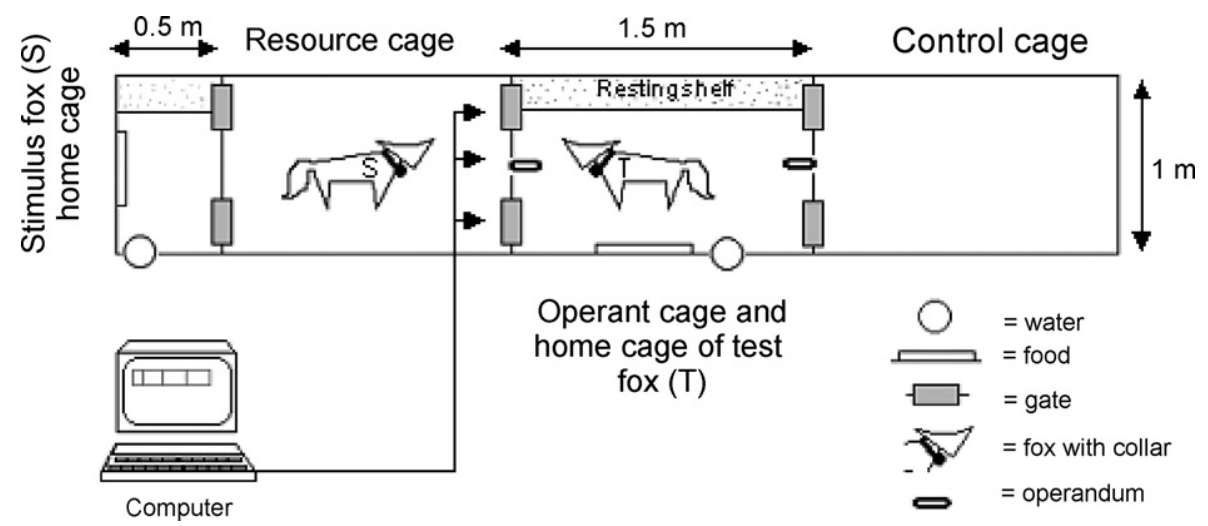

Fig. 1. The operant apparatus. During the social trial both foxes had shared access to the resource cage. The stimulus fox had exclusive access to the stimulus fox cage whereas the test fox had exclusive access to the operant compartment and the control cage. 
the door was kept open for $10 \mathrm{~s}$ to allow the fox to enter before it was closed automatically.

Each apparatus was mounted on stilts $1 \mathrm{~m}$ above ground level and a total of five units of the apparatus were used. They were placed $2 \mathrm{~m}$ apart in parallel rows inside the shed. Thus, the experimental animals could see and hear each other during the experiments, just like foxes in typical farm housing. Because the foxes had previously completed parallel tests as juveniles, they were well trained and habituated quickly to the apparatus (for a detailed description of training, see Hovland et al., 2008).

\subsection{Altering costs of access}

The reinforcement schedule used was 'differential reinforcement of high rates' (DRH: Chance 1999), wherein a certain number of pulls must occur within a fixed amount of time. A punishing effect can arise if responding is too slow, or if the subject delivers pulls at random, because when the timer 'zeros out' the subject has to start all over again to complete the schedule. The DRH schedule ensures that the animal keeps on working at a constant rate and may generate extremely high rates of responding (Chance 1999). Based on previous tests (Hovland et al., 2008), a schedule allowing four seconds per pull was chosen, exemplified by a demand of 512 pulls within $32 \mathrm{~min}$. Prior to the start of trials, the foxes were put on a fixed ratio schedule of 1 (FR1) for a habituation period of 1-6 days. Then, an ascending series of costs was imposed, the cost being increased every $24 \mathrm{~h}$ until the fox stopped visiting the resource. The cut-off used for determining the maximum price paid was $12 \mathrm{~h}$, i.e. implying that the test fox had not visited the shared compartment within the available time before 09:00 pm. The response schedule was then returned to FR1 for a minimum of 2 days, or until all the remaining subjects had completed the trial.

Costs were increased stepwise at 08:00 am each day using an individual cost schedule for each test fox. Individual schedules were used in an attempt to standardise the test duration and were calculated based on these subjects' previous maximum prices for food paid in an earlier study (Hovland et al., 2008). To illustrate, in the previous study where these foxes worked on similar schedules, the gap between the first and last fox reaching their maximum price for social contact was 25 days. Since foxes' social motivations may change with season, especially towards the reproduction season, we needed to equalise the length and timing of the testing period across subjects. In the individual schedules, the number of daily cost levels up to the previous maximum price for food was set to equal approximately 28 for each subject, predicting 4 weeks of operant testing, assuming that the previous maximum price paid (MPP) remained the upper response threshold. The schedules for each test subject, up to a possible 40 days of testing should each animal exceed its previous MPP, are illustrated in Table 1.

\subsection{Operant trial for social contact}

Prior to putting the animals within the apparatus they were weighed and a patch of fur on the tail of each test
Table 2

Ethogram of behaviours recorded during social interaction in the operant test.

\begin{tabular}{|c|c|c|}
\hline & Behaviours & Description \\
\hline Event & Agonistic gape & $\begin{array}{l}\text { Open mouth signal } \\
\text { directed towards other fox } \\
\text { (not 'open-mouthed play } \\
\text { face') }\end{array}$ \\
\hline Event & Aggression & $\begin{array}{l}\text { Aggressive signals like back } \\
\text { arching, blocking, } \\
\text { mounting, uprights and } \\
\text { short attacks }(<5 \mathrm{~s})^{\mathrm{a}}\end{array}$ \\
\hline State & Fight & $\begin{array}{l}\text { Attack ( }>5 \mathrm{~s} \text { ) followed by } \\
\text { wrestling (upright) and } \\
\text { bites directed towards the } \\
\text { opponent }\end{array}$ \\
\hline Event & Social play & $\begin{array}{l}\text { Play signals }{ }^{\mathrm{a}} \text { that involve } \\
\text { the partner in all or parts of } \\
\text { the play sequence }\end{array}$ \\
\hline Event & $\begin{array}{l}\text { Social sniffing and } \\
\text { grooming }\end{array}$ & $\begin{array}{l}\text { One fox sniffs and/or } \\
\text { grooms the other }\end{array}$ \\
\hline Event & Nose-to-nose contact & \\
\hline State & $\begin{array}{l}\text { Synchronous rest with } \\
\text { contact }\end{array}$ & $\begin{array}{l}\text { Foxes rest in bodily contact } \\
\text { with each other in the } \\
\text { resource cage }\end{array}$ \\
\hline State & $\begin{array}{l}\text { Synchronous rest without } \\
\text { contact }\end{array}$ & $\begin{array}{l}\text { Foxes rest without bodily } \\
\text { contact in the resource } \\
\text { cage }\end{array}$ \\
\hline
\end{tabular}

a See Tables 1 and 2 in Hovland et al. (2008) for a more detailed description of these behaviours.

subject was removed for individual recognition (stimulus animals were left unmarked). Subsequently, collars were put on and the animals placed inside the apparatus. The foxes were given $12 \mathrm{~h}$ access between 08:00 and 21:00 $\mathrm{h}$ to the resource cage each testing day. From 21:00 to 08:00 h they were locked in their respective home cages with additional access to a chewing bone. The gates between the cages were closed by metal plates and the operant devices removed from the home cage of the test subjects. Gates were reopened, the chewing bone removed and operant devices put back at 07:45 h the next day. The stimulus animals' gates were always opened first and closed last, giving them between 12.5 and $13 \mathrm{~h}$ accessibility to the resource cage. Subjects were given 1 day on FR1 to habituate to the apparatus and stimulus fox. They then had 6 days of access on FR1 prior to the access costs were raised, during which time behavioural data were collected (see next section). To examine foxes' baseline level of contact before and after the test they also had a similar 6 days of access to the resource cage on FR1 after they reached the maximum price: this was to check for consistency in social behaviour over the 4 weeks of the experiment (see previous note concerning possible seasonal effects). The foxes were fed in the operant cage ad libitum once a day and water was replenished three times a day. The test ran between 26 th November and 26th December 2007.

\subsubsection{Recordings of social behaviour}

Subjects were videotaped continuously using infrared colour video cameras (480 TVL, model YC-25V). The frequencies of various social behaviours (Table 2) were recorded for $20 \mathrm{~min}$ at three different cost levels (FR1-median-maximum price), comprising a total of $60 \mathrm{~min}$ for 4 of the pairs and $52.5 \mathrm{~min}$ for one pair (no. 2) 
that had only limited time in social contact. Also, the total durations of synchronous resting and physical aggression $>5 \mathrm{~s}$ from FR1 throughout all cost levels to maximum price, i.e. over the whole experiment, were also recorded (Table 2). Because several behaviours appeared at low frequencies they were pooled for analysis. Several behaviours were recorded as events each time they occurred regardless of their duration (see Table 2), and as new events when they were interrupted by any other behavioural acts. Synchronous resting, in contrast, was recorded as a state; its duration was thus recorded, and the proportion of time each pair spent resting together with/without contact during the observation period was calculated.

\subsubsection{Operant trial for social contact - other data collected}

The number of visits to the resource cage per cost, total time spent inside the resource cage per cost and mean visit duration to the resource cage per cost were calculated for the test subject and the stimulus fox. In addition, visit number and duration to the control cage was calculated for the test subject. Since the stimulus fox was free to leave the resource cage when the test fox was present, we also calculated total time spent together in the resource cage per cost. To describe the pattern of social interaction when contact was almost free (FR1) the above-mentioned time and visit variables were also calculated for the test fox and the stimulus fox at FR1 both before and after the costs increased to check for any changes over time (e.g. with season). These measures were calculated based on six $12 \mathrm{~h}$ periods on FR1: days 2-7 on FR1 before the costs increased and days 2-7 after the maximum price had been paid.

\subsection{Operant trial for food}

To calculate the relative motivational strength for social contact, the vixens' maximum price paid for access to food, a commonly used yardstick resource was also measured. For this, test foxes had access to the resource cage and the control cage for $12 \mathrm{~h}(08: 00-21: 00 \mathrm{~h})$ each day of the test. The five subjects were weighed before being placed inside the apparatus and then given 1 day for habituation on FR1 prior to the start of the trial. The cost level was increased at 08:00 am each day, on the same individual schedules as used in the social trial. No stimulus foxes were present during this test. The same procedure was used as in the social trial for locking foxes inside their home cages at 21:00 $\mathrm{h}$. The food was provided in a bowl tethered to the wire mesh floor inside the resource cage. The ration size was approximately $450 \mathrm{~g}$ standard wet paste for fur animals delivered at 08:15 each day. During the experiment, the intake of individual subjects was also monitored on a daily basis. If some food remained uneaten on 2 consecutive days, the ration was slightly reduced to avoid a possible loss of appetite and/or aversion to leftover food (Hovland et al., 2007). The food consisted of 50\% protein, $33 \%$ fat and $17 \%$ carbohydrate with a metabolizable energy content of $115 \mathrm{kcal} / 100 \mathrm{~g}$. Water was available from drinking cups in the operant cage and replenished three times a day. The trial ran from 9th January to 20th February 2008.

\subsection{Data collected in both trials}

In both trials, the maximum price paid (MPP) was recorded as the price paid the day before a fox stopped visiting the resource. The relative price paid (RPP) for contact was calculated as each fox's maximum price for social contact divided by her maximum price for food. The test fox in pair no. 4 that paid the highest price for access to food had to be stopped just before she reached the maximum price (visit no. was low) for food due to problems with the operandum. It is therefore possible that her true calculated RPP for social contact was somewhat lower than reported in the results.

\subsection{Hypotheses to be tested}

Our principle hypotheses $(\mathrm{H})$ and predictions $(\mathrm{P})$ were as follows:

$\mathrm{H}_{1}$ : Adult vixens perceive operant work as costly. $\mathrm{P}_{1}$ : Visits to the resource cage will decline both for social contact and food as the FR increases. $P_{2}$ : Each vixen will reach a level at which she cannot/will not work for $12 \mathrm{~h}$.

$\mathrm{H}_{2}$ : Adult vixens are socially motivated. $\mathrm{P}_{1}$ : The test foxes will perform operants to access conspecifics. $\mathrm{P}_{2}$ : They will voluntarily spend time together (e.g. the stimulus fox will not always withdraw when the test fox enters the resource cage).

$\mathrm{H}_{3}$ : Vixens' social motivations are stable over the entire experimental period. $\mathrm{P}_{1}$ : Food Test 1 results predict foxes' responses in Food Test 2. $\mathrm{P}_{2}$ : Responses in the Food Tests predict behaviour in the Social Operant trials. $\mathrm{P}_{3}$ : Social interactions in the pre-operant trial F1 period predict those in the post-operant trial F1 period.

$\mathrm{H}_{4}$ : The nature of the social interactions predicts the magnitude of social motivation. $\mathrm{P}_{1}$ : Test subjects in pairs characterised by aggression will pay a lower relative maximum price for social contact. $\mathrm{P}_{2}$ : Test subjects in pairs typified by high levels of affiliative behaviours will have a higher relative maximum price for social contact.

\subsection{Statistical analyses}

Differences in agonistic behaviours between Food Tests 1 and 2, differences in maximum prices paid between food and contact, and the time and visit data from the operant tests, including the behavioural data were analysed with paired samples $t$-tests (SAS, 1990). To assess how increasing access costs affected the test foxes' use of the resource cage, the regression lines for each fox were calculated for the number of visits against the costs as increased every $24 \mathrm{~h}$. Gradients were then compared with no decline using a one-sample $t$-test against an expected slope of zero. Correlations between variables of interest were investigated using Pearson correlation tests. All mean values are given with standard errors (SE). JMP version 8 (SAS institute) was used for all analyses. 


\subsection{Ethical note}

During all tests involving social contact the foxes were given additional supervision to allow intervention in the case of harmful aggression (though in practice this never occurred). In the Social Trial, all foxes also had the opportunity to withdraw from further contact and potential aggression by retreating to their respective home cages. In both operant trials, the foxes were checked visually by the animal caretaker three times a day. As mentioned above, the 'cut-off for calling a cost level the maximum price paid was that the foxes stopped visiting the resource for $12 \mathrm{~h}$; in the Food Trial, this implied that foxes were denied food for one day. Subsequent to recording their maximum price paid, the cost was set to FR1 and, to compensate, they were offered extra food. The foxes were also weighed ( mean \pm SD) before (Social Trial: test foxes $=7.5 \pm 0.64 \mathrm{~kg}$; Social Trial: stimulus foxes $=7.5 \pm 1.5 \mathrm{~kg}$ and Food Trial: test foxes $=7.2 \pm 0.66 \mathrm{~kg}$ ) and after each trial. On average, their body weight decreased slightly during the Social Trial (test foxes $=-0.28 \pm 0.19 \mathrm{~kg}[-3.7 \%]$; stimulus foxes: $-0.37 \pm 0.12 \mathrm{~kg}[-4.9 \%])$ and the Food Trial $(-0.17 \pm 0.32 \mathrm{~kg}$ $[-2.4 \%])$, but these changes are considered to be within the normal weight range (for comparison see Hovland and Bakken, 2010). The study was approved by the Norwegian Animal Research Authority (Ref. no.: 11/06).

\section{Results}

\subsection{Food competition tests and assessment of dominance relations}

In the food competition tests, aggressive displays tended to be more frequent than positive interactions when data from both tests were merged $\left(t_{(4)}=2.16, P=0.097\right)$, although this was not significant in either Food Test 1 $\left(t_{(4)}=1.53, P=0.202\right)$ or Food Test $2\left(t_{(4)}=1.01, P=0.370\right.$; Fig. 2). The percentage of observations involving agonistic interactions (Fig. 2) also tended to be higher in Food Test 1 $(9.8 \pm 3.99 \%)$ than in Food Test $2(3.8 \pm 1.52 \%)\left(t_{(4)}=2.24\right.$,
$P=0.089$ ). The relationships between such behaviour in these tests and behaviour in the social operant trials are presented below.

None of the vixens in any of the pairs were willing to compete for access to the restricted amount of food in either of the food competition tests. Typically, both vixens ate at the same time or took turns in front of the food tray without any aggression. Thus, it was impossible to establish clear dominance relations based on these tests.

\subsection{Responses to cost increases, and maximum prices paid (MPP) for access to an adult vixen and food}

In the Social Operant Trial, the test subjects tended to visit the resource cage less frequently with increasing costs $\left(t_{(4)}=2.23, P=0.089\right.$; Visit no. Social: FR1 $=11.0 \pm 4.9$, $\mathrm{MPP}=1.6 \pm 0.5)$. The same decline in visit number occurred during the Food Operant Trial $\left(t_{(4)}=3.36, P=0.028\right.$; Visit no. Food: FR $1=17.6 \pm 10.3, \mathrm{MPP}=1.4 \pm 0.5)$. Thus the increase in FR was indeed costly. The average MPP that subjects were willing to pay for access to another vixen was $560 \pm 160.6$ pulls, while that for food was $2108 \pm 526.6$ pulls. The MPP for social contact was significantly less than the MPP for food $\left(t_{(4)}=4.07, P=0.015\right)$, and the relative price paid (RPP) for contact was approximately $24.8 \pm 3.36 \%$ of the price paid to access food, although this varied individually from 16.1 to $36.6 \%$ (see Table 4 for individual differences). The number of days between the first and last test subject reached maximum price for social contact was 7 , i.e. the individually tailored schedules successfully helped ensure that all subjects were tested over a similar time period (see Section 2).

\subsection{Visits to the resource cage, control cage and time spent together when visits were almost free (FR1)}

On average, when access was almost free, pairs spent about $1 / 6$ of the available time together (Fig. 3) and behaviour seemed stable over the 5 weeks of the experiment. The total interaction time and total time spent in

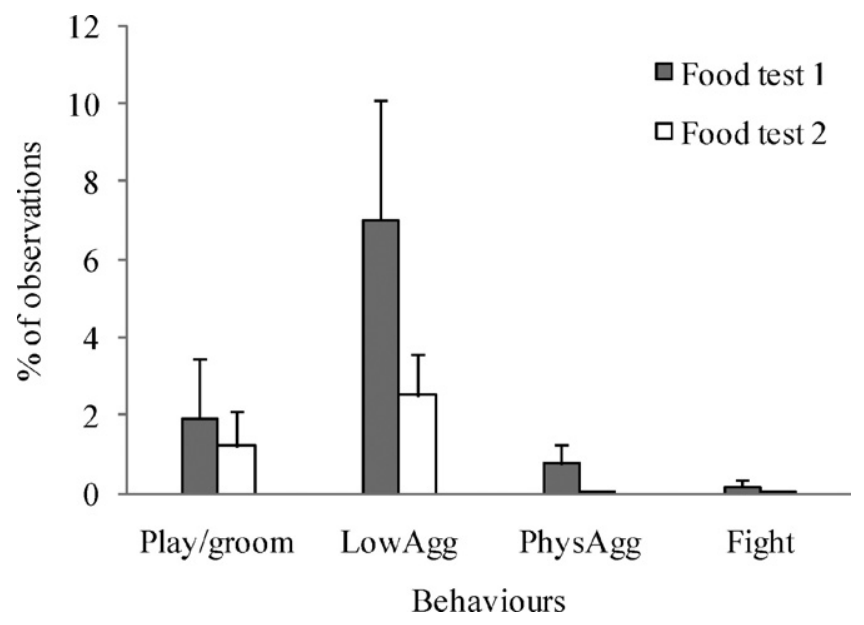

Fig. 2. The average level of agonistic interactions (mean $\pm S E$ ) within pairs of adult vixens in Food Tests 1 and 2 . The values are given as percentages of total observations. Abbreviations: LowAgg = agonistic gaping, back arching; PhysAgg = upright, blocking, mounting. 
Table 3

Visit no. $( \pm S E)$ and mean visit duration $( \pm S E)$ to the resource cage for the test and stimulus fox on FR1 before the costs increased and after maximum price was paid. Differences between means were not statistically significant $(P>0.110)$.

\begin{tabular}{|c|c|c|c|c|}
\hline & \multicolumn{2}{|l|}{ Test fox } & \multicolumn{2}{|c|}{ Stimulus fox } \\
\hline & Visit no. & Mean duration & Visit no. & Mean duration \\
\hline Before costs increased & $12.9 \pm 2.4$ & $13.6 \pm 3.2 \mathrm{~min}$ & $23.8 \pm 3.5$ & $33.3 \pm 5.7 \mathrm{~min}$ \\
\hline After maximum price was paid & $12.1 \pm 1.5$ & $17.2 \pm 2.1 \mathrm{~min}$ & $27.7 \pm 4.9$ & $29.0 \pm 5.9 \mathrm{~min}$ \\
\hline
\end{tabular}

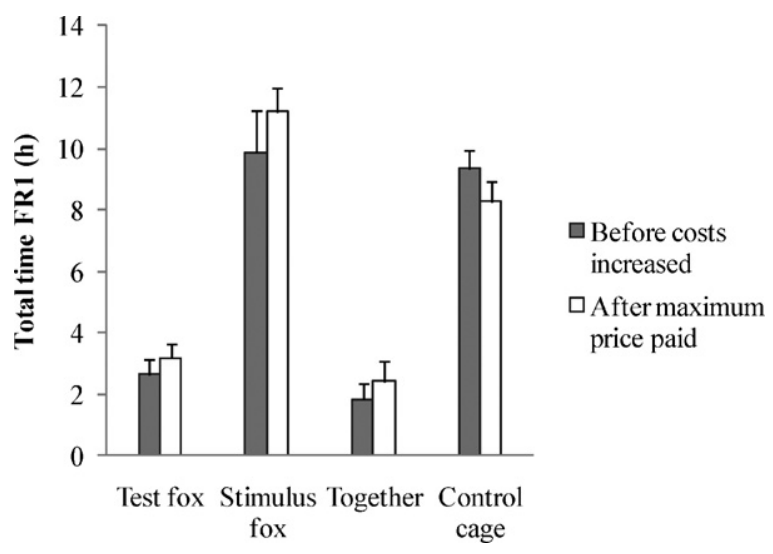

Fig. 3. Mean $( \pm \mathrm{SE})$ total time $(\mathrm{h})$ spent inside the resource cage before costs increased and after maximum price was paid for the test and stimulus fox when the test fox's access costs were low (a fixed ratio schedule of 1, FR1) and mean total time spent together per $12 \mathrm{~h}$. In addition, the test fox time (mean $\pm \mathrm{SE}$ ) spent in the free control cage before costs increased and after maximum price was paid is given.

the resource cage at FR1 before the costs were increased ('before') and after MP was paid ('after') are shown for the test and stimulus fox in Fig. 3. Neither the test nor the stimulus foxes' time inside the resource cage differed significantly between the two time periods (test fox: $t_{(4)}=1.09, P=0.336$, stimulus fox: $\left.t_{(4)}=2.05, P=0.110\right)$. Time spent together in the resource cage also did not significantly differ 'before' and 'after' $\left(t_{(4)}=1.60, P=0.185\right.$, Fig. 3 ). Furthermore, the patterning of social behaviour was similar before and after the costly trials: thus neither the test nor the stimulus foxes significantly changed their visit rate or their average visit duration between the two time periods $(P>0.110$, Table 3$)$. There was also a tendency towards a strong, positive correlation between time spent together in the resource cage 'before' and 'after' $(r=0.82, P=0.087)$. Thus, overall the behaviour seems stable across the experiment. There was also a strong positive correlation between the stimulus foxes' visit number to the resource cage 'before' and 'after' ( $r=0.95, P=0.015)$, although this did not hold for the test fox $(r=-0.62, P=0.261)$.

The stimulus foxes (for whom access was completely free) spent significantly more time inside the resource cage than the test subjects, both 'before' $\left(t_{(4)}=4.57, P=0.010\right.$ ) and 'after' $\left(t_{(4)}=16.77, P<0.0001\right)$. Likewise, the number of visits and average visit duration was also higher in stimulus foxes compared to test foxes, both 'before' (visits: $t_{(4)}=2.46$, $P=0.069$, duration: $t_{(4)}=5.33, P=0.006$ ) and 'after' (visits: $t_{(4)}=3.57, P=0.024$, duration: $\left.t_{(4)}=2.95, P=0.042\right)$.

\subsection{Behaviour during social interaction in the social operant trial}

Fig. 4 shows the various behaviours recorded during social contact in the resource cage. The number of events of aggressive behaviour (abbreviated 'AgoGape', 'PhysAgg' in Fig. 4) was higher than the number of positive events (abbreviated 'social play', 'sniff/groom', 'nose-to-nose' in Fig. 4) in four out of five pairs, but a paired $t$-test showed no statistical significant difference $\left(t_{(4)}=1.28, P=0.271\right)$. However, when the time spent together was summed up for the whole experimental period, the vixens spent on average $10 \mathrm{~h} 46 \mathrm{~min} \pm 4 \mathrm{~h} 41 \mathrm{~min}$ resting synchronously in the same cage (i.e. together, with or without physical contact). This made up $43.0 \pm 9.7 \%$ of the total time spent together during the experiment. In contrast, the total time spent in aggression (duration $>5 \mathrm{~s}$ ) during the whole experimental period was on average just $21.6 \pm 20.4 \mathrm{~min}(6.2 \pm 4.3 \%)$ of total time spent together.

\subsection{Individual differences between the pairs, and their relationships with dominance and RPP for social contact}

The five pairs seemed to differ in their nature and degree of social behaviour, reflecting different social motives for visiting the resource cage. Table 4 lists the relative prices paid (RPP) per test subject, and some of the behaviours and time variables recorded during the operant test. Thus in contrast to the other pairs, pair nos. 3 and 4 that paid

Table 4

Individual values for key time and behaviour variables recorded during social interaction. Variables: The relative price paid for social contact (RPP); number of gaping signals (gaping), duration (in min) of upright postures and fights $>5 \mathrm{~s}$ (Upr/fight); mean time (h) spent in shared compartment at FR1 before costs increased (contact FR1-start) and mean time (h) spent in shared compartment at FR1 after maximum price was paid (contact FR1-end); the sum of time spent in the shared compartment during the cost increase (sum contact); and the proportion of time spent resting synchronously in bodily contact (RBC).

\begin{tabular}{|c|c|c|c|c|c|c|c|}
\hline Pair & RPP & Gaping & Upr/fight & Contact FR1-start & Contact FR1-end & Sum contact & $\mathrm{RBC}$ \\
\hline 1 & $22.6 \%$ & 66 & $1 \mathrm{~min} 57 \mathrm{~s}$ & $3 \mathrm{~h} 03 \mathrm{~min}$ & $2 \mathrm{~h} 53 \mathrm{~min}$ & $17 \mathrm{~h} 31 \mathrm{~min}$ & $0 \%$ \\
\hline 2 & $22.6 \%$ & 284 & $3 \mathrm{~min} 00 \mathrm{~s}$ & $0 \mathrm{~h} 38 \mathrm{~min}$ & $0 \mathrm{~h} 10 \mathrm{~min}$ & $1 \mathrm{~h} 23 \mathrm{~min}$ & $0 \%$ \\
\hline 3 & $36.6 \%$ & 51 & $80 \min 09 \mathrm{~s}$ & $2 \mathrm{~h} 43 \mathrm{~min}$ & $3 \mathrm{~h} 50 \mathrm{~min}$ & $45 \mathrm{~h} 56 \mathrm{~min}$ & $4.3 \%$ \\
\hline 4 & $26.1 \%$ & 169 & $22 \min 38 s$ & $2 \mathrm{~h} 02 \mathrm{~min}$ & $3 \mathrm{~h} 24 \mathrm{~min}$ & $32 \mathrm{~h} 44 \mathrm{~min}$ & $0.4 \%$ \\
\hline 5 & $16.1 \%$ & 56 & $99 \min 07 \mathrm{~s}$ & $0 \mathrm{~h} 44 \mathrm{~min}$ & $1 \mathrm{~h} 52 \mathrm{~min}$ & $7 \mathrm{~h} 16 \mathrm{~min}$ & $0 \%$ \\
\hline
\end{tabular}




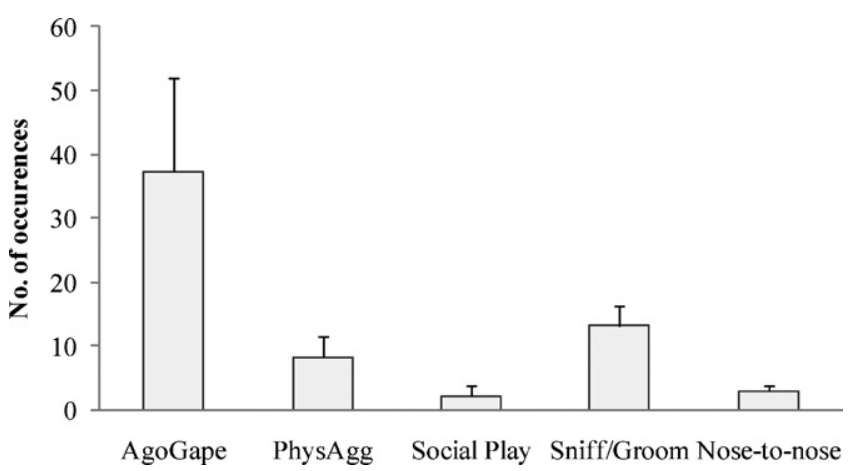

Fig. 4. Mean frequencies per $20 \mathrm{~min}$ of the social behaviours recorded as events that occurred during contact in the operant apparatus. Average values (mean \pm SE) are calculated based on three 20 min observation periods per pair (FR1, medium cost level and MP).

the highest RPPs for contact seemed to spend more time in contact when access was almost free (FR1), and spent the most total time together and rested together in bodily contact (Table 4 ). The foxes of pair no. 2 , in contrast, spent the least time together, and had also the highest levels of aggression (Table 4). Although the test fox in pair no. 2 paid a maximum price of DHR448 to access the resource cage, no interactions between the two foxes occurred as of DHR64; that is, for the six last days before the test fox stopped paying.

To assess whether the strengths of vixens' social motivations were related to whether their interactions were typically affiliative or aggressive, correlations were run between RPP and behaviours related to both positive motivations (synchronized rest, social play, nose-to-nose contact, allo-grooming) and negative motivations (physical aggression, gaping, uprights and fights). There was a significant positive correlation between total time in synchronized rest and RPP $(r=0.89, P=0.046$; Fig. 5$)$; and between synchronized resting in contact and RPP $(r=0.90$, $P=0.04$ ). Total time spent together during the cost increase also tended to positively correlate with social motivation as inferred from $\operatorname{RPP}(r=0.87, P=0.054)$. The other aforementioned behaviours were not significantly correlated with $\operatorname{RPP}(P>0.269)$.

The levels of total aggression in Food Test 2 were positively correlated with the total level of aggression (agonistic gape and aggression) during the operant test ( $r=0.91$, $P=0.031$, Fig. 6). In contrast, none of the positive behaviours

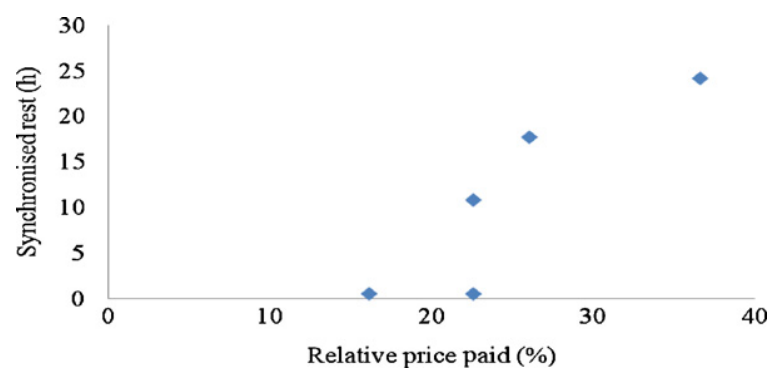

Fig. 5. The relationship ( $r=0.89, P=0.046)$ between total time $(h)$ spent in synchronous resting in the shared resource cage and relative price paid (RPP, \%) for social contact.

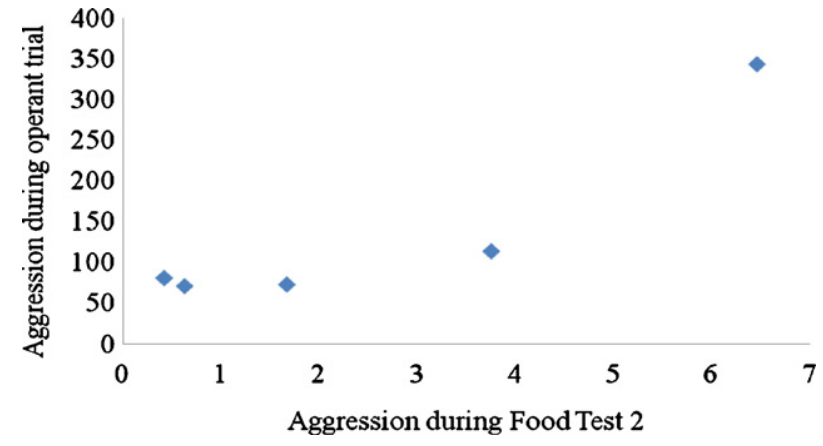

Fig. 6. The relationship ( $r=0.91, P=0.031)$ between total level of aggression (percentage of total observations) during Food Test 2 in November and aggression (total number of agonistic gapes and aggressive displays) during the operant social trial in December.

in Food Tests 1 and 2 significantly predicted the level of positive behaviours during the operant test $(P>0.25)$.

\section{Discussion}

Here, we examined various aspects of adult vixens' motivations for full contact with another vixen and their social behaviour before and during operant testing. Due to the small number of animals in this study we cannot draw large-scale conclusions about the strength and nature of social motivation in adult vixens in general; however, the data do illustrate that in principle social contact can be enriching, and they also provide useful information on how and why social motivations vary.

\subsection{Measuring dominance relations}

The food competition test, commonly used to establish dominance rank in farmed animals (e.g. Langbein and Puppe, 2004) did not elicit the vixens' motivation to monopolise food despite being denied food for $24 \mathrm{~h}$ prior to testing. This was somewhat surprising because the test is usually successful in establishing dominance relations in juvenile silver foxes as shown by e.g. Bakken (1993) and Akre et al. (2010a). Probably, this indicated a low competitive motivation which was also reflected by the low level of aggressive displays (see further discussion below). 


\subsection{The strength of social motivations}

The test vixens were willing to continue their visits to the shared compartment with increasing costs, both for social contact and food, which showed that both these resources were rewarding to the animals. Adult vixen valued full social contact on average about $24 \%$ of the worth they put on food: a relatively low value, and also, on average, lower than the value these females placed on social contact when sub-adults, at the age of 7-8 months, which averaged 38\% of the MPP for food (Hovland et al., 2008). The social behaviours of adult vixens also differed from juvenile vixens in several ways. As juveniles, the vixens had spent almost half of the day together when access were free, but as adults these vixens spent just $1 / 6$ of disposable time in contact, again further indicative of a lowered motivation to socialize in adults. Potential explanations include changes in the relative value of food; effects of season; the fact that adult vixens were allowed only $12 \mathrm{~h}$ access compared to $24 \mathrm{~h}$ access in the previous study of sub-adults; differences in the nature (e.g. sociality) of the stimulus animals, as well as changes in the social motivation of the test foxes. Also, the lack of physical contact for more than 2 years could possibly affect adult vixens' social motivation and behaviour (in, e.g. male rats, previous studies have shown that social isolation during adulthood reduces social exploration and induces high emotional response to a novel social environment (Shoji and Mizoguchi, 2011)); although since the vixens could see, smell and communicate through the wire mesh the potential effect of isolation was possibly reduced compared to that of total isolation. Overall the evidence suggests genuine reductions in sociality with age. First, the nature of adult vixens' interactions seemed more competitive with higher, relative levels of aggressive displays compared to when juvenile (Hovland et al., 2008; Fig. 5). Second, one rewarding aspect of social contact that may decline with age and thus reduce animals' motivation for contact is social play (Spinka et al., 2001; Trezza et al., 2009). Pair housed adult silver fox vixens tend to engage in social play less frequently than do pair housed juvenile vixens housed under similar conditions (Hansen, 2007; Akre et al., 2010b). Intriguingly, the number of social play bouts was highest in the pair where the test subject paid the lowest relative price for contact, suggesting that reinforcing properties of play may indeed be reduced for adults, perhaps because play sequences include competitive elements that may escalate into aggression (e.g. Bekoff et al., 1981). Overall the difference between adult and sub-adults suggests that housing sub-adults may be more beneficial than socially housing adults.

\subsection{The nature of adult vixens' relationships}

The nature of vixens' relationship examined in connection with Food Test 1 (October) and Food Test 2 (November) reflected a lack of strong competitive motivations and was mainly characterized by low-intensive agonistic displays. Apart from a few short attacks in two pairs in the food competition tests, there was no serious aggression throughout the whole experiment. Also, the frequency of agonistic interactions seemed to decrease from Food Test 1 to Food
Test 2. These data resemble findings of previous studies in socially housed adult silver fox vixens showing that the level of aggression was at its lowest in November compared to October and December (Brøste, 2010; Hovland and Bakken, 2010). The level of agonistic behaviour during the second test in November was predictive of later aggressive interactions, making it potentially useful as a screening method for identifying compatible cage mates.

On average, the test subject's total time spent with the stimulus fox did not change significantly from the start to the end of the experiment, further indicating that the social motivations of each pair were stable over the course of testing. However, pairs did seem to differ from each other in the type and degree of social interaction, and in the degree to which contact was rewarding. In this type of set-up where animals are completely free to leave (and reunite with) the social partner, interaction time may possibly act as a valid indicator of social motivation within pair because the time in shared contact is based on active choices made by both animals. To illustrate, pair no. 2, in which foxes spent the least total time together, also had the highest level of gaping signals during the operant testing and stopped interacting at DHR64 (despite the test subject's continued visits to the shared compartment). As suggested by the high number of gaping signals, the motives for seeking contact in test subject no. 2 may thus have been predominantly aggressive. Motivations for intraspecific contact are not always for positive interactions, but may be for competition and aggression, as previously demonstrated in, e.g. mice (May and Kennedy, 2009) and silver fox males (Hovland et al. 2006). Consequently, such aggressive motives may thus have been one of the reasons why the stimulus animal avoided further contact.

Physical aggression during the operant trial constituted mostly of upright displays which sometimes escalated into fights. However, these fights did not appear to be severe, especially since no injuries were observed. Moreover, it was at times difficult to categorize these behaviours as purely aggressive since they sometimes also included elements of play. Nevertheless, these interactions were quite likely related to mutual assessment of strength (and status) and therefore had clear competitive aspects. The time spent performing physical aggression seemed substantial in two of the pairs ( 3 and 5), however, compared to the total interaction time this constituted $2.9 \%$ and $22.7 \%$ of the time, respectively. In general, there was no significant negative correlation between time spent in physical aggression and level of social motivation; however, the pair (no. 5) with the lowest RPP also had the highest aggression level. The existence of such potential relationships should therefore be re-examined with larger sample sizes. High levels of aggression may devalue potential benefits of social contact, maybe especially in carnivores that are capable of inflicting serious bite injuries, making withdrawal opportunities particularly important. As the test subjects' spent three times as long in the control cage than the shared compartment when access to both was free, this strongly suggests that the opportunity to withdraw from social interaction was also important.

Nevertheless, the bulk of the time the foxes spent together was peaceful, involving resting together (about 
$40 \%$ of the time vixens spent together was used for synchronous resting). Furthermore, the strength of social motivation was positively related to this synchronous resting behaviour. Thus the strongest motives for seeking contact may be related to a need to feel secure during periods of increased vulnerability, like, e.g. during sleep. Social resting in close physical contact was also observed in the two pairs that paid the highest relative prices for contact; this behaviour may indicate the greatest social tolerance (Van Loo et al., 2004).

\subsection{Concluding remarks}

In summary, adult silver fox vixens were motivated for social contact with a same-aged vixen, and social interactions were largely amicable. However, their maximum price paid for contact was far lower than their motivation for food. Furthermore, the motives for seeking contact varied between subjects, and related to aggression, as well as to social resting. Due to some subjects' aggressive intentions for seeking social contact social environments for adult vixens should ideally include opportunities for retreat in case of aggression; an arrangement which may be difficult to achieve under commercial conditions. Alternatively, social caging could be preceded by robust tests for social compatibility; something our food competition tests suggest is possible.

Future studies of sociality and social housing in farmed foxes should replicate this work on a larger scale, to build up a fuller picture of the prevalence of aggressive versus affiliative relationships across multiple pairs. In particular, it would be interesting to replicate our two Food Tests to assess how the order or season of the test affects its ability to provide reliable predictive information on stable aspects of vixen-vixen relationships. They could also replicate the social operant trials at different times of year, to investigate whether sociality changes with hormonal status; and include longitudinal studies of pairs of females that are raised together from cub-hood, to study how vixen sociality changes with age and social experience.

\section{Acknowledgements}

This study was supported by the Norwegian Research Council and the Norwegian Fur Breeders' Association. Thanks to the staff at the university research farm for taking good care of the animals and for valuable help in monitoring the experiment.

\section{References}

Akre, A.K., Hovland, A.L., Bakken, M., 2010a. Do different competition strategies affect social preference and behaviour in silver fox vixens (Vulpes vulpes)? Appl. Anim. Behav. Sci. 126, 59-66.

Akre, A.K., Hovland, A.L., Bakken, M., 2010b. The effects of resource distribution on behaviour in pair housed silver fox vixens (Vulpes vulpes) subsequent to mixing. Appl. Anim. Behav. Sci. 126, 67-74.

Bakken, M., 1993. The relationship between competition capacity and reproduction in farmed silver fox vixens. J. Anim. Breed. Genet. 110, 147-155.

Baker, P.J., Funk, S.M., Harris, S., White, P.C.L., 2000. Flexible spatial organisation of urban foxes, Vulpes vulpes, before and during an outbreak of sarcoptic mange. Anim. Behav. 59, 127-146.
Bekoff, M., Tyrrell, M., Lipetz, V.E., Jamieson, R., 1981. Fighting patterns in young coyotes: initiation, escalation, and assessment. Aggressive Behav. 7, 225-244.

Brøste, H.W., 2010. Effects of different cage environments on social behaviour and some behavioural welfare indicators in adult pair housed silver fox (Vulpes vulpes) vixens in autumn. MSc Thesis. Department of Animal and Aquacultural Sciences (IHA), Norwegian University of Life Sciences (UMB).

Cavallini, P., 1996. Variation in the social system of the red fox. Ethol. Ecol. Evol. 8, 323-342.

Feh, C., de Mazieres, J., 2003. Grooming at a preferred site reduces heart rate in horses. Anim. Behav. 46, 1191-1194.

Hansen, C., 2007. Effects of solitary versus pair housing and different cage environment on some behavioural welfare indicators in young silver fox (Vulpes vulpes) vixens. MSc Thesis. Department of Animal and Aquacultural Sciences (IHA), Norwegian University of Life Sciences (UMB).

Harris, S., White, P.C.L., 1992. Is reduced affiliative rather than increased agonistic behaviour associated with dispersal in red fox? Anim. Behav. 44, 1085-1089.

Holm, L., Jensen, M.B., Jeppesen, L.L., 2002. Calves' motivation for access to two different types of social contact measured by operant conditioning. Appl. Anim. Behav. Sci. 79, 175-194.

Hovland, A.L., 2005. Development and evaluation of an operant method to measure social motivation in farmed silver foxes (Vulpes vulpes). Dr. Scient. Thesis 2005:14. Department of Animal and Aquacultural Sciences, Norwegian University of Life Sciences (UMB). ISBN: 82-5750656-7.

Hovland, A.L., Mason, G., Ahlstrøm, Ø., Bakken, M., 2007. Responses of farmed silver foxes (Vulpes vulpes) to excessive food availability: implications for using food as a yardstick resource in motivation tests. Appl. Anim. Behav. Sci. 108, 170-178.

Hovland, A.L., Mason, G.J., Kirkden, R.D., Bakken, M., 2008. The nature and strength of social motivations in farmed silver fox vixens (Vulpes vulpes). Appl. Anim. Behav. Sci. 111, 357-372.

Hovland, A.L., Akre, A.K., Bakken, M., 2010. Group housing of adult silver fox (Vulpes vulpes) vixens in autumn: agonistic behaviour during the first days subsequent to mixing. Appl. Anim. Behav. Sci. 126, 154-162.

Hovland, A.L., Mason, G., Bøe, K.E., Steinheim, G., Bakken, M., 2006. Evaluation of the 'maximum price paid' as an index of motivational strength for farmed silver foxes (Vulpes vulpes). Appl. Anim. Behav. Sci. 100, 258-279.

Hovland, A.L., Bakken, M., 2010. Group housing of adult silver fox (Vulpes vulpes) vixens during autumn and its consequences for body weight, injuries and later reproduction: a field study. Appl. Anim. Behav. Sci. $127,130-138$.

Iossa, G., Soulsbury, C.D., Baker, P.J., Edwards, K.J., Harris, S.H., 2009. Behavioral changes associated with a population density decline in the facultatively social red fox. Behav. Ecol. 20, 385-395.

Jensen, M.B., Pedersen, L.J., 2008. Using motivation tests to assess ethological needs and preferences. Appl. Anim. Behav. Sci. 113 340-356.

Kirkden, R.D., Edwards, S.S., Broom, D.M., 2003. A theoretical comparison of the consumer surplus and the elasticities of demand as measures of motivational strength. Anim. Behav. 65, 157178.

Kirkden, R.D., Pajor, E.A., 2006. Using preference, motivation and aversion tests to ask scientific questions about animals feelings. Appl. Anim. Behav. Sci. 100, 29-47.

Langbein, J., Puppe, B., 2004. Analysing dominance relationships by sociometric methods-a plea for a more standardised and precise approach in farm animals. Appl. Anim. Behav. Sci. 87, 293315.

Macdonald, D.W., Creel, S., Mills, M.G.L., 2004. Canid society. In: Macdonald, D.W., Sillero-Zubriri, C. (Eds.), Biology and Conservation of Wild Canids. Oxford University Press, NY.

Mason, G.J., Cooper, J., Clarebrough, C., 2001. Frustrations of fur-farmed mink. Nature 410, 35-36.

May, M.E., Kennedy, C.H., 2009. Aggression as positive reinforcement in mice under various ratio-and time-based reinforcement schedules. J. Exp. Anal. Behav. 91, 185-196.

Oliveira, A.F.S., Rossi, A.O., Silva, L.F.R., Lau, M.C., Barreto, R.E., 2010. Play behaviour in nonhuman animals and the animal welfare issue. J. Ethol. 28, 1-5.

Patterson-Kane, E.G., Hunt, M., Harper, D., 2002. Rats demand social contact. Anim. Welf. 11, 327-332.

Pedersen, et al., 2002. Social isolation affects the motivation to work for food and straw in pigs as measured by operant conditioning techniques. Appl. Anim. Behav. Sci. 77, 295-309. 
SAS, 1990. SAS Users Guide: Statistical Version 6, 4th ed. Statistical Analysis System Institute, Cary, NC, 1686 pp.

Seaman, S.C., Waran, N.K., Mason, G., D'eath, R.B., 2008. Animal economics: assessing the motivation of female laboratory rabbits to reach a platform, social contact and food. Anim. Behav. 75, 31-42.

Shoji, H., Mizoguchi, K., 2011. Aging-related changes in the effects of social isolation on social behavior in rats. Physiol. Behav. 102, 5862.

Spinka, M., Newberry, R., Bekoff, M., 2001. Mammalian play: training for the unexpected Q. Rev. Biol. 76, 141-168.
Trezza, V., Damsteegt, R., Vanderschuren, L.J.M.J., 2009. Conditioned place preference induced by social play behavior: parametrics, extinction, reinstatement and disruption by methylphenidate. Eur. Neuropsychopharmacol. 19, 659-669.

Van Loo, P.L.P., Van de Weerd, H.A., Van Zutphen, L.F.M., Baumans, V., 2004. Preference for social contact versus environmental enrichment in male laboratory mice. Lab. Anim. 38, 178-188.

White, P.C.L., Harris, S., 1994. Encounters between red foxes (Vulpes vulpes): implications for territory maintenance, social cohesion and dispersal. J. Anim. Ecol. 63, 315-327. 